\title{
A POESIA E AS OUTRAS ARTES
}

\section{POETRY AND THE OTHER ARTS}

\author{
Lucia Santaella \\ PUC - SP - Pontifícia Universidade Católica de São Paulo \\ Winfried Nöth \\ University of Kassel
}

\begin{abstract}
RESUMO: As relações da poesia com as outras artes é extremamente complexa pelo menos por duas razões: em primeiro lugar porque são relações que vêm se transformando ao longo do tempo; em segundo lugar porque as artes tendem a se tornar cada vez mais híbridas a partir do advento do computador como meta-mídia. Tomando por base uma visão semiótica dessas questões, este artigo visa mapear algumas das relações entre a poesia e as outras artes, com especial atenção para as afinidades entre a poesia e a música nas suas múltiplas facetas, passando para as relações entre a poesia e as artes visuais para terminar nas novas reflexões que a contemporaneidade das mídias está exigindo de nós.
\end{abstract}

PALAVRAS-CHAVE: semiótica; poesia e música; poesia e artes visuais; literatura multimídia.

ABSTRACT: The relations between poetry and the other arts are extremely complex at least for two reasons: in the first place because they are relations that have historically been transformed; in the second place because the arts tend to become more and more hybrid since the advent of the computer as a metamedia. Taking a semiotic point of view on these questions, this article aims at mapping some of the relations between poetry and the other arts with special attention to the affinities between poetry and music in their diverse facets. Then the relations between poetry and the visual arts are explored to end in new reflections which the new media are demanding from us.

KEYWORDS: semiotics; poetry and music, poetry and the visual arts, multimedia literature.

\section{A moldura semiótica}

A semiótica, o estudo geral dos signos e sistemas de signos, fornece uma estrutura para o estudo da literatura que visa a alargar o âmbito do foco restrito apenas aos signos verbais para o escopo mais amplo de um locus criativo de confluência de signos verbais com muitos outros tipos e modalidades de signos. A tendência a uma abordagem demasiado estreita da literatura tem sido incentivada por uma tradição que designa as artes verbais como "literatura", um termo cuja raiz latina Littera (letra) define a ênfase na escrita e na leitura em detrimento dos aspectos orais e auditivos das artes verbais tanto na forma acústica de poemas escritos quanto na tradição da literatura oral. 
A abordagem semiótica da literatura, ao contrário, enfatiza a plurimodalidade e a multimidialidade das artes verbais e amplia seu foco para incluir os vários contextos visuais e acústicos não verbais com os quais os textos literários também estão associados. A semiótica alarga o horizonte da sintaxe e da semântica literárias para incluir a pragmática literária como o estudo dos processos sígnicos estéticos (semioses) nas artes verbais.

\subsection{O quadro da semiótica das artes verbais e das outras artes}

Em correlação com os três ramos clássicos da semiótica, há três modos fundamentais pelos quais os signos verbais estão associados com os não verbais na semiose literária: contiguidade ou justaposição (sintaxe), representação (semântica) e interpretação (pragmática).

O estudo da dimensão sintática da literatura, no sentido mais amplo, é o estudo do verbal na contiguidade com signos não verbais. As artes não verbais com as quais as artes verbais estão em contiguidade são, sobretudo, a música, as artes do corpo e as outras artes visuais. As artes verbais sempre estiveram intimamente ligadas a todas as outras artes, embora o grau com que essa ligação tenha sido feita tenha apresentado variações ao longo da história da literatura. Ela tem sido mais forte no gênero literário do teatro com suas extensões do verbal para as artes visuais, artes do corpo do ator, mímica e dança, as artes visuais da moda (vestimentas), design de objetos e esculturas, pintura (cenário) e arquitetura (palco). Em menor grau, a simultaneidade de signos verbais e não verbais tem sido uma característica das artes retóricas do gesto, mímica e a arte do movimento do corpo nos gêneros oratória, como eulogia, discurso funeral, sermão ou homilia. A retórica antiga e medieval tinha um ramo especial, chamado de actio, para ensinar as formas adequadas de movimento do corpo em associação com os discursos de oratória. Associações com a música instrumental e vocal podem ser encontradas na poesia oral e em gêneros poéticos, como a balada, por exemplo, na arte dos bardos medievais e trovadores. A transição da literatura para os gêneros musicais, como o Lied, a ópera, ou música coral é apenas uma questão das convenções das divisões canônicas das artes e seus gêneros.

Em sua dimensão semântica, a literatura está associada a todas as outras artes na medida em que representa essas artes e seus signos por meio de representações verbais. Textos literários descrevem pinturas, esculturas ou obras de arquitetura, música e dança; eles expressam ou evocam as impressões provocadas por tais obras de arte em personagens literários e nos tratados teóricos, como a ArsPoetica, de Horácio (na música), ou no Laocoonte, de Lessing (em pintura e escultura), refletem sobre as diferenças específicas e as características comuns da literatura e as outras artes. Sem referência a qualquer arte canônica específica, a literatura evoca, descreve, ou reflete sobre o visual, o acústico, os sinais gustativos ou olfativos, por meio da evocação, descrição, associação ou sinestesia, como no poema de Rimbaud,Vogais, que associa as vogais A, E, I, U, e O com as cores preto, branco, vermelho, verde e azul, respectivamente.

Entre os recursos literários ou gêneros em que as reflexões sobre a literatura e as outras artes são centrais, encontram-se a ekphrasis e a paragone (comparação). Ekphrasis é um texto verbal que descreve uma obra de arte visual, tradicionalmente, um elogio poético da beleza de uma pintura ou de uma escultura. A paragone, que pode ser uma obra de arte verbal ou visual, visa a dar respostas para a questão da supremacia de uma das artes irmãs na competição entre o acústico, o visual e as artes literárias (MITCHELL, 1994).

Em sua dimensão pragmática, a literatura está associada com as outras artes nos processos de semiose literária como resultado de leituras e interpretações da poesia e da 
prosa. A literatura evoca sentimentos, (re)ações, imagens mentais ou convenções, muitas vezes, não distintos daqueles evocados por outras artes, e, em processos intertextuais e intermidiáticos da semiose estética, a literatura influencia e é, portanto, uma causa, o tão chamado pré-texto de outras obras de arte, como pinturas de gênero de cenas mitológicas, óperas, filmes ou obras de arte multimídia (ver PRAZ, 1974).

\subsection{Três matrizes semióticas da literatura e das artes}

Subjacentes à multiplicidade de signos e processos sígnicos de que as linguagens estéticas e outras linguagens são compostas, existem três matrizes semióticas: a matriz acústica, a visual e a verbal (SANTAELLA, 2001). Apesar da grande variedade de meios e canais e das diferenças consideráveis entre as mídias como fotografia, cinema, televisão, vídeo, jornal, ou rádio, todos os processos sígnicos e todas as formas estéticas e gêneros, quer seja a música, a literatura, o teatro, o desenho, a pintura, a escultura, a gravura, a arquitetura, o vídeo etc., todos eles podem ser subsumidos por uma dessas três matrizes, resultando na maioria das vezes de misturas e combinações entre as matrizes.

No domínio da literatura, essa teoria das três matrizes da linguagem e do pensamento encontra respaldo em Ezra Pound que, no seu $A B C$ da literatura (1970), postula três categorias fundamentais para explicar todos os processos poéticos: a melopeia, a fanopeia e a logopeia. Melopeia, de acordo com esta poética, refere-se à dimensão acústica das artes verbais, a sua dimensão auditiva, sua musicalidade e ritmo. A fanopeia responde pela dimensão visual e imagética, pela miríade de imagens que a literatura pode evocar, enquanto a logopeia dá conta do impacto verbal, lógico e linguístico da literatura. De acordo com esses três processos da poiesis literária, Pound também distingue três maneiras de alcançar a perfeição literária:

(a) por saturação acústica das palavras na sua fusão com os sons,

(b) pela projeção de uma imagem na retina mental e

(c) por meio "da dança do intelecto entre as palavras".

Uma fundação semiótica das três matrizes fundamentais das artes também pode ser encontrada nas três categorias universais de primeiridade, secundidade e terceiridade da semiótica de C. S. Peirce (ver SANTAELLA, 1983). Primeiridade, de acordo com Peirce, é a categoria de ipseidade, dos fenômenos considerados em si mesmos, sem relação com qualquer outra coisa. Isto é evidentemente fundamental para a melopeia de Pound, pois o universo acústico é o universo da primeiridade. A categoria da secundidade diz respeito às relações de polaridade, ego e não ego, interior e exterior, ação e reação. É o que predomina na fanopeia, universo da imagem, em particular, das imagens que representam ou indicam o mundo, que o retratam sob efeito de uma insistência perceptiva. Terceiridade é a categoria dos signos convencionais e do pensamento lógico. Por isso é a categoria que melhor corresponde à logopeia, o universo da mente humana, do pensamento e intelecto.

Peirce elaborou uma teoria semiótica dos processos sígnicos com base em não mais do que três categorias fundamentais das quais se origina uma pluralidade de misturas (1931-58). De modo similar, Pound escreveu sobre as misturas de suas três categorias em obras da literatura, concluindo que grande literatura é simplesmente linguagem carregada de significado até o máximo grau possível. Linguagem repleta de significado é linguagem com o menor grau de definição e maior potencial de significado. Essas são também as características semióticas pelas quais Umberto Eco (1965) caracterizou a abertura estética das obras de arte 
da vanguarda do século 20. Assim, qualquer que seja a modalidade - melopeia, fanopeia, ou logopeia - e quaisquer que sejam as misturas entre elas, uma grande obra de arte tenderá sempre para a predominância da categoria da pura possibilidade qualitativa, que é uma característica da categoria peirceana de primeiridade. Grande literatura é sempre marcada pela indeterminação e por um alto envolvimento dos sentidos na interpretação do seu significado impreciso. A música é o protótipo de uma arte que atende a essas características e, por essa razão, Pound postula que a poesia nunca deve distanciar-se da música, pois a poesia começa a atrofiar quando fica muito longe da música.

No entanto, enquanto a música não é nada além de som e pura combinação sonora, a literatura é significado em sua densidade máxima. "A música não significa nada", Igor Stravinsky afirmou certa vez. Seria melhor dizer "não representa nada". Mas, por não representar nada, a música pode representar tudo, e isso explica seu grande poder sugestivo. Literatura, por outro lado, trabalha com palavras que, por sua própria natureza, são unidades de representação. Porque carrega as palavras com o grau máximo de possibilidades de sentido, a literatura quer representar tudo, mas, na sua totalidade, é confrontada com o abismo do silêncio e do nada, o umbigo do sonho-mundo.

\subsection{A literatura como sistema secundário de signos}

A literatura é um complexo sistema de signos estéticos cujos constituintes são emprestados de outro sistema de signos complexos, nomeadamente a língua. Os elementos da literatura são elementos do sistema de signos da língua: fonemas, palavras, frases, textos etc. A música, pelo contrário, cria obras de arte cujos elementos têm apenas uma função semiótica bastante fraca fora do sistema de música: os sons de um clarinete ou de um piano pouco ou nada significam fora de seus contextos musicais, visto que o substrato semiótico da música não é nem o ruído, nem outros sons da natureza e da cultura.

Artistas visuais também criam obras de arte em um sistema semiótico cujos elementos não são emprestados de outro sistema de signos culturais. Um pintor, que pinta em tinta a óleo sobre tela, cria signos estéticos a partir de materiais que dificilmente podem ser encontrados fora do repertório sígnico dos pintores: a cor da tinta a óleo, o cavalete, o pincel, a tela etc. A sintaxe e a semântica da "linguagem" da pintura não têm circulação fora dos estúdios dos pintores e da moldura de suas pinturas. Embora existam relações naturais, especialmente icônicas, entre as figuras, formas e cores de uma pintura e as figuras e formas que ela representa, o repertório sígnico de um pintor não pode ser considerado independentemente do sistema da pintura. Trata-se, portanto, de um sistema semiótico que não é culturalmente utilizado de forma distinta para qualquer outra finalidade.

Por ser procedente de um outro sistema semiótico, o sistema da língua, só a literatura é um sistema semiótico secundário, enquanto a música e as artes visuais são essencialmente sistemas semióticos primários, no sentido de que seus materiais e componentes não servem a nenhum outro propósito semiótico além de serem partes de uma obra de arte. No entanto, por diferentes razões, as artes aplicadas também podem se aproximar da noção de um sistema semiótico secundário, uma vez que dão forma a elementos e materiais que têm funções práticas em uma determinada cultura e, portanto, têm significados culturais independentes das artes que os moldam. Arquitetura e design de produtos, por exemplo, são sistemas que transformam objetos não estéticos em signos estéticos, mas esses objetos, por exemplo, portas, tetos, paredes, quartos, coberturas, copos ou vasos, são signos no sistema da cultura cotidiana, antes de serem transformados em signos estéticos. 
CASA, Vol.9 n.2, dezembro de 2011

\section{Poesia, linguagem e música}

Das muitas relações entre literatura e as outras artes, uma das mais fundamentais é aquela que se dá entre a poesia e a música. Música e literatura oral são artes do tempo, e essa característica comum a ambas é a razão pela qual a poesia está mais estreitamente relacionada com a música do que com as artes visuais, que são as artes do espaço, ou, como Lessing (1986) argumentou, música e literatura oral são artes cujos signos apresentam-se em sequência temporal e não em contiguidade espacial. Poesia e música relacionam-se de várias maneiras, e há muitas abordagens para o estudo histórico, geográfico, étnico e cultural dessas relações. As considerações a seguir incidirão sobre os aspectos semióticos de tais relações.

\subsection{A oralidade do discurso e o canto}

Com exceção da mão humana e, é claro, do cérebro, não há provavelmente nenhuma outra parte do corpo humano tão plurifuncional quanto a boca. São várias as funções por ela desempenhadas, tais como respirar, sugar, comer, saborear, beijar, falar e cantar. A boca humana não é somente um órgão para satisfazer necessidades fisiológicas básicas, mas também um órgão envolvido na sensação de prazer. Do ponto de vista da psicanálise, a boca é um órgão de pulsão psíquica e, como tal, nunca poderá satisfazer o desejo humano. Enquanto respirar e comer se referem a necessidades humanas básicas, a degustação já adiciona um elemento de prazer à necessidade. Beijar, por sua vez, é um excedente para a exuberância insaciável do prazer.

O corpo humano não tem nenhum órgão especializado estritamente para a função da fala. Em vez disso, existem vários órgãos com diferentes funções biológicas não linguísticas cuja combinação constitui o aparelho da fala. Além disso, falar não só serve ao propósito de comunicação e interação. Falar, também, pode produzir um excedente de prazer. Assim como a função de comer proporciona o prazer na degustação, falar fornece um excedente de prazer no canto. A fascinação do canto é o encanto da voz transformada em prazer.

\subsection{O substrato musical da fala e a poesia}

O aparelho vocal humano funciona de modo similar a um instrumento musical. Para servir a seu propósito, ele interage com um número de sub-órgãos e órgãos associados: os pulmões, os lábios, as cordas vocais, a traqueia, a faringe e a laringe, a cavidade oral, a úvula, o palato macio e o palato duro, a língua, a cavidade nasal, os dentes e os lábios. Vibrações no ar, os pontos de articulação, o fechamento e liberação do fluxo de ar, fricções nasais, orais e as possibilidades de distinguir entre sons contínuos e descontínuos significam que a fala, em suas origens fisiológicas, é respiração articulada e vocalização, do silêncio ao sussurro, murmúrio, fala e grito.

Em sua materialidade sensorial, a fala humana é pura qualidade: cada voz tem seu timbre particular, tom, altura, intensidade e duração com suas variáveis específicas. Todas as línguas têm uma musicalidade própria e diferem em seus padrões de altura da voz. Cada idioma tem seu próprio inventário de vogais palatais e velares, consoantes tensas e relaxadas, plosivas e contínuas, sílabas tônicas e átonas, que associam as formas fonéticas com diferentes modos de expressão musical. 
No entanto, uma vez que as palavras não são apenas sons, mas servem como veículos de comunicação de ideias, o substrato musical da expressão verbal é, muitas vezes, nada mais do que o suporte material do discurso utilizado para fins de comunicação. Além disso, a familiaridade dos falantes com a sua própria língua reduz a consciência do perfil acústico do discurso de modo que as propriedades acústicas e qualidades musicais da língua passam desapercebidas no uso diário. É por isso que esquecemos ou não percebemos como a nossa própria língua soa. Todavia os compositores de todos os tempos têm mostrado que é possível recuperar as qualidades da voz humana com a sua articulação específica da fala, o que reaviva os laços sensíveis entre a fala e a música, ao chamar atenção para as qualidades fonéticas da fala.

Sempre que o foco se coloca na qualidade da fala, somos confrontados com as forças de atração e repulsão, fluxos e refluxos, correspondências e reverberações, sons e silêncios e as muitas outras formas de variações do design de som que associam a fala com a música. A música é, portanto, um substrato da fala. Quando coloca em evidência a materialidade acústica sensível, a fala se insurge contra as tiranias das abstrações que são próprias do discurso verbal cotidiano. Sempre que uma tal materialidade se torna evidente, as sementes da poesia se fazem presentes.

Assim como a poesia é profundamente marcada por sua afinidade com a música, no jogo de suas configurações, a música também evidencia estruturas que são características da função poética da linguagem as quais se manifestam nas mais diversas formas de projeções da similaridade sobre o eixo da contiguidade (JAKOBSON, 1971). Se a música aproxima-se da poesia, é no núcleo de suas linguagens, lá onde a música da poesia é entrelaçada com a poesia da música, que ambas as artes se irmanam. Poesia e música são construções da forma, jogo de estruturas, ecos e reverberações, progressão e regressão, sobreposição e inversão. Em suas estruturas em filigrana, uma peça musical bem como um poema são, acima de tudo, diagramas. Poetas e músicos são diagramadores da linguagem.

\subsection{Ritmo, língua e poesia}

Ritmo, a variação temporal da fala com respeito ao comprimento de suas sílabas, à frequência de suas pausas e à variação de seus padrões de acentuação, é um concomitante natural da língua falada, com fortes apelos sensoriais. A sinestesia pode fazer o ritmo também perceptível como uma impressão tátil. Quanto mais no centro da atenção auditiva, mais o ritmo tende a ser sentido em um continuum qualitativo de sensações. Além disso, o ritmo também está presente em nossos fluxos de pensamento. Quanto mais lúcido for o fluxo do pensamento, tanto mais ele toma a forma do ritmo. Nem audível, nem visível, mas progredindo e regredindo entre os diversos impulsos de seus influxos interiores, o fluxo do pensamento progride ritmicamente no fluxo das associações que dá origem a novas ideias.

Além do ritmo das palavras na continuidade da fala e das ideias nas linhas do pensamento, existem ainda tanto o ritmo dos ciclos da natureza biológica, quanto o ritmo do corpo humano perceptível na respiração e na contração sistólica e relaxamento diastólico do coração batendo. Nossa consciência de todos esses ritmos é devida à nossa constituição humana de seres pensantes, condição que nos torna prisioneiros do tempo, mas, paradoxalmente, ao mesmo tempo, livres para questionar o tempo. Nas raízes da linguagem da música, encontra-se o âmago da busca humana pelas formas do tempo. Podemos pensar sobre o tempo de uma perspectiva biológica, física ou filosófica. A música, por sua vez, não pensa sobre o tempo, ela pensa o tempo. Pensar o tempo é criar padrões ou fluxos rítmicos. 
Se, na música, o ritmo é uma relação entre unidades de tempo, subdivisão do tempo em durações, interrogar o tempo é criar figuras rítmicas, desenhar durações.

$\mathrm{Na}$ maior parte das vezes, confundimos o ritmo musical com as noções de compasso, pulso, velocidade de pulso e acento. Essas noções estão imbricadas, mas não se confundem.

Compasso é uma fatia abstrata do tempo. Cada compasso compreende certo número de pulsos, regularmente organizados segundo um padrão característico de acentos. Compasso é uma forma de medida, metro, métrica. [...] O pulso é uma sucessão regular de batimentos imaginários regulando a execução temporal de uma obra. Acelerar o pulso é tocar mais rápido, isto é, reduzir proporcionalmente todas as durações; retardar o pulso é tocar mais lento, alongar proporcionalmente todas as durações. [...] Já o ritmo é uma subdivisão do tempo em durações. Qualquer sequência de durações é rítmica; se as durações são racionalizadas, tornar-se-ão também incidentalmente métricas. [...] O compasso pode abrigar qualquer figura rítmica e o ritmo pode ser compreendido e escrito segundo as mais diversas métricas. O ritmo é independente da métrica (NESTROVSKI, 1986, p. 103).

Assim como a música, a poesia também pode ser feita de pancadas de acentos, organizadas em pulsações regulares e métrica racionalizada. Mas, assim como na música, metro e ritmo, embora possam coexistir, não são a mesma coisa.

Os metros são históricos enquanto que o ritmo se confunde com a própria linguagem. [...] O metro é medida abstrata... A única exigência do metro é que cada verso tenha sílabas e acentos requeridos. Em si mesmo, o metro é medida vazia de sentido. O ritmo, pelo contrário, jamais se apresenta sozinho; não é medida, mas conteúdo qualitativo e concreto (PAZ, 1972, p. $13)$.

Foi preciso que a poesia, no verso livre, se entregasse à aventura do ritmo, nas correntezas subjacentes da fala, rebelando-se contra a versificação silábica, para que o ritmo pudesse aparecer na nudez de sua autonomia, desprendido das roupagens da métrica. Do mesmo modo, na música contemporânea eletroacústica, foi preciso que a gestualidade rítmica se pusesse na contracorrente da sua secular submissão às convenções de pulso e metro, para que o ritmo pudesse emergir nas figurações de sua liberdade (ver SANTAELLA, 2001, p. 97 184).

A música é, sobretudo, ritmo, mas não é só ritmo. O seu grande desafio está nos modos como engenhosamente engendra e agrega os outros parâmetros do som à unidade permitida pelo ritmo. Embora extraia a unidade de sua composição, antes de tudo, da força agregadora do ritmo, a poesia também põe conjuntamente em ação outros parâmetros do som e além do som. Se a música é feita de sons, a poesia é feita de palavras. As palavras são sons, mas ao mesmo tempo, algo além e aquém do som. É nesse ponto que se dá a distinção entre poesia e música.

\subsection{Poesia, música e suas artes irmãs}

A história da música ocidental é também a história da escritura musical. Aliás, sem a partitura, a evolução contínua das formas musicais não teria sido viável, pois é, na escritura, que são geradas as condições para a reflexão sobre as formas. Pensamento que se 
debruça na exploração das variações possíveis das formas. Ao trazer para o poema indagações sobre estruturas da partitura musical, Mallarmé preencheu o universo da escritura poética com a densidade secular do pensamento das formas levado a cabo pela escritura musical, detonando a evidência de que, por baixo dos sons audíveis, existe uma outra música inaudível, aquela que é feita dos movimentos constelares da música das formas.

A música é feita, sobretudo, para ser ouvida, mas quando a música se adensa no pensamento das formas, junto ao som, o ouvido passa a inteligir o movimento das estruturas: progressão, reversão, retrogradação, espelhamentos, polaridades, a lógica interna das sequências e das sobreposições, as configurações do ritmo. Ora, esse universo das estruturas é um universo originário que pode se manifestar tanto nas formas audíveis quanto visíveis, feitas para a tatilidade dos sentidos, assim como nas formas do pensamento. É isso provavelmente que Goethe tinha em mente quando disse que a arquitetura é música congelada. Também na arquitetura, unidades formais se configuram em repetições e variações que vão criando padrões rítmicos. As figurações das estruturas e dos ritmos não são privilégios exclusivos da música.

Entretanto, diferentemente da música, a arquitetura tem uma função utilitária primordial, enquanto a música não apresenta nenhuma servidão referencial nem de usos prédeterminados, pois ela é feita de configurações em estado puro, despojadas das misturas adventícias que são próprias das linguagens que cumprem a função representativa. Por essa razão, quando qualquer linguagem aciona o mergulho na pureza de sua materialidade, é sempre a música que é tomada como paradigma. É a essa condição da música que outras artes aspiram. Isso se dá porque a música é, sobretudo, o limite da redução das formas de pensamento à materialidade das formas. Por isso mesmo, Santaella (2001, p. 103-112), considerou a música como a manifestação privilegiada, senão única, do quali-signo icônico, remático que, na classificação dos signos de Peirce, é aquele tipo de signo que não pode representar outra coisa senão puras formas: "Nenhum Ícone puro representa nada além de Forma, nenhuma Forma pura é representada por nada a não ser um Ícone [...], pois, em precisão de discurso, os Ícones nada podem representar além de Formas e Sentimentos" (CP 4.544).

As linguagens plásticas, bi ou tridimensionais, também podem ser reveladoras da música das formas, sobretudo quando estão libertas da representação de um referente, quer dizer, quando não indicam, nem convencionalmente representam algo que está fora delas, mas exploram tão só e apenas as qualidades sensíveis de seus próprios materiais: cor, luz, textura, brilho, massas, proporção, volume, ritmos etc. Isso costuma ser chamado de arte abstrata. Infelizmente, pois o rótulo de "abstrata" oculta a dimensão sensorial que as cores, linhas, sobreposições, direções e movimentos, pontos de tensão, polaridade, equilíbrio e relaxamento configuram.

Não é por acaso que Kandinsky (2010), quando descobriu ou foi surpreendido pela pureza sensual dos materiais pictóricos, encontrou na música o território privilegiado para as correspondências e afinidades das combinatórias cromáticas da pintura. Também não é por acaso que Mondrian, na sua obstinada perseguição da harmonia e do ritmo nas variações entre linhas retas e cores primárias, acabou por encontrar no booggie wooggie um paradigma rítmico que ele buscou plasmar em forma visível.

Se, no contexto das linguagens plásticas, a música das formas já se faz sentir, o que dizer do cinema ou vídeo, uma vez que essas linguagens colocam concreta e materialmente as linguagens em movimento? Trata-se de um movimento plástico no tempo das imagens, tomadas e planos que duram um certo tempo e que desvanecem nas pontuações dos cortes para reaparecerem sob uma outra forma, na duração de um novo plano, e assim por 
diante (ver SANTAELLA e NÖTH, 1998, p. 93). Isso é ritmo, subdivisão do tempo em durações, tal como na música, com a diferença de que, nas imagens em movimento, são os olhos que apalpam, ou melhor, são os olhos que auscultam o ritmo, verdadeiro sistema nervoso central das imagens em movimento.

\section{A estética da escrita, das formas visuais e da poesia}

Com a sua transposição do espaço acústico para o visual, a linguagem verbal passou a se fixar em um suporte material que congela a aparição sempre evanescente do idioma falado. O que perde do sopro e dos grãos da voz, a linguagem ganha em eternidade. É por isso que ainda hoje podemos ler antigos escritos. No entanto, ao fixar o som em uma forma visual convencional e repetitiva, a escrita alfabética perde as qualidades sonoras da expressão, seu tom, altura, timbre, intensidade e duração, bem como perde os movimentos rítmicos do corpo humano associados à fala: respiração, vibração, pausas, síncopes e todas as demais ondulações que dão vida à fala humana.

\subsection{A poética da escrita: Oriente e Ocidente}

A poesia no Ocidente, mesmo quando deixou de ser cantada, e mais ainda porque deixou de ser cantada, foi, durante muito tempo e, em alguns casos, ainda continua a ser, busca de reencarnação, na escritura, da aurora musical da fala. "O meio de aprender a música do verso é escutá-la”, diz Pound.

No entanto, a grafia tem uma constituição plástica que lhe é própria. Não por acaso, no decorrer de 35 séculos, todas as vezes que ocorreram mudanças de suporte ou de meios para o registro da escritura - da pedra ao couro, do couro ao papiro, do papiro ao papel, do papel às telas eletrônicas - essas mudanças se fizeram acompanhar pelo restabelecimento imediato de considerações estéticas sobre bases artísticas que envolvem questões relativas à forma, espaço, procedimentos e legibilidade. Via de regra, a dimensão plástica da escrita tende a ser ignorada pelos estudiosos das línguas, porque estes, sempre mais interessados em conteúdos do que em meios, tendem a negligenciar essa área da forma visual, enquanto que é para ela que a pesquisa específica do artista sempre se voltou.

Foi preciso que o Ocidente chegasse à revolução industrial e, de lá para cá, à sofisticação crescente dos meios de impressão e reprodução da escritura para que a veia de libertação da linguagem escrita se fizesse sentir. Libertação da escrita em relação à sua submissão ao som. É assim que, de um mero epifenômeno da fala, a escritura passou a assumir o risco e desafio de sua própria materialidade. Sem se desprender do som porque ela já nasce habitada pelo som, a realidade plástica da escritura se tornou força visível complementar do audível.

Com a variação dos tipos gráficos - gesticulação da escrita - com a distribuição diversificada da linguagem impressa na diagramação jornalística, abriram-se, para a página branca da escritura, novos umbrais até então insuspeitados.

Os caminhos da poesia no ocidente e oriente foram muito diferentes. A razão mais fundamental para essa diferença está nas suas formas opostas de escritas. No Ocidente, a poesia nasceu com a música, poesia feita para ser cantada, portanto, uma poesia marcada pela oralidade. Também marcada pela oralidade foi a escrita ocidental, escrita fonética, baseada na articulação combinatória dos sons. Para melhor compreender essa questão, Pound (1970: 26) nos fornece uma descrição breve e precisa das diferentes formas de escrita: 
Para começar do começo, vocês provavelmente sabem que há uma linguagem falada e uma linguagem escrita, uma baseada no som e outra baseada na vista. Falamos a um animal com meia dúzia de ruídos e gestos simples. O relato de Lévy-Bruhl sobre as línguas primitivas da África assinala linguagens que ainda se acham presas à mímica e ao gesto. Os egípcios acabaram por usar figuras abreviadas para representar sons, mas os chineses ainda usam figuras abreviadas como figuras, isto é, o ideograma chinês não tenta ser a imagem de um som ou um signo escrito que relembre um som, mas é ainda o desenho de uma coisa; de uma coisa em uma dada posição ou relação, ou de uma combinação de coisas. O ideograma significa a coisa, ou a ação ou situação ou qualidade pertinente às diversas coisas que ele configura.

No Ocidente, contudo, a escritura seguiu por outras vertentes. A descoberta do alfabeto fonético foi, antes de tudo, a descoberta da fantástica economia que preside ao sistema fonológico dos idiomas. Os idiomas falados nascem da combinatória regrada, do campo delimitado de um número finito e altamente reduzido de sons. $\mathrm{O}$ alfabeto não é senão a tradução plástica desses sons. Som transposto para a imagem do som.

\subsection{Poesia visual entre a literatura e as artes gráficas}

O potencial estético comum ao verbal e às artes visuais, bem como as transições e transformações da tipografia e da página impressa para imagens gráficas foram explorados pelos autores na tradição da poesia visual. Primeiramente, a poesia estendeu seu potencial criativo do espaço acústico para o espaço visual com os carmina figurata da antiguidade grega, poemas-padrão escritos como inscrições que desenham no espaço o contorno de um objeto. A tradição dos carmina figurata foi revivida nos tempos barrocos, mas permaneceu esquecida até a redescoberta do potencial gráfico da literatura no século 20. Lewis Carroll (1871, A Cauda de Rato) e Guillaume Apollinaire, com seu calligrammes, retomou a tradição antiga dos poemas-padrão. Il pleut, de Apollinaire (Chove, 1918), por exemplo, consiste de palavras dispostas em longas linhas verticais sugerindo chuva.

A poesia visual atingiu seu clímax com a Poesia Concreta na década de 1950 e 1960. Em contraste com a tradição da poesia-padrão, a poesia concreta não se restringe à criação de poemas na forma de um objeto, mas vai mais longe em seu uso experimental do espaço tipográfico. O rebento mais recente da poesia visual é a poesia digital, que combina o potencial estático, que o visual compartilha com a pintura ou a gravura, com o potencial dinâmico das artes do tempo, como cinema e vídeo arte. Com o seu Lance de dados (1897), um poema que abandona o arranjo linear do texto escrito e quebra todas as regras de sintaxe e tipografia para transmitir a ideia de que "Todo pensamento é um lance de dados", foi Mallarmé quem inaugurou uma nova era na literatura ocidental na qual a poesia começou a emancipar-se de sua vocação tradicional de representar a linguagem falada.

Por estar impresso em uma forma similar a uma partitura musical, o poema mallarmaico restaurou as associações com a música que pareciam estar perdidas. Mallarmé, ele mesmo declarou que a fonte de inspiração para a escritura do seu poema havia sido a música de concerto e os arranjos de suas notações nas páginas de uma partitura. 


\subsection{Escrita ideográfica: diagramas do pensamento}

Quando o Ocidente se pôs em estado de alerta para a dimensão plástica da linguagem escrita, foram os horizontes da música das formas que essa dimensão descortinou para a poesia. Separadas, durante séculos, pela diversidade das origens, a poesia ocidental e a oriental-ideogramática descobriram, então, seus laços comuns, junto à revelação, no Ocidente, de que, nas raízes de sua poesia, já operavam, desde sempre, fatores ideogrâmicos da linguagem verbal (ver FENOLLOSA, 1969 e CAMPOS, 1977).

Mesmo quando a poesia não explora as possibilidades do corpo das letras no espaço da página em configurações visíveis, ainda assim há um extrato poético de relações internas sonoras, sintáticas e semânticas que configuram uma diagramação da linguagem. Essa diagramação inclui o aspecto sonoro das palavras, mas não se limita a ele. Trata-se de aliterações, coliterações, paronomásias e anagramas que vão criando fluxos e refluxos de sentidos, antecipações e regressões semânticas, redistribuições e cruzamentos de palavras ou partes de palavras tanto na linha horizontal (palavras depois de palavras) quanto na vertical (palavras sob ou sobre palavras) e diagonal (palavras entre palavras). Essas relações compõem equações sintáticas e semânticas, diagramas internos animados pela lei das correspondências, pela força de atração das analogias. Tem-se aí uma outra lógica que se aproxima dos processos ideogrâmicos de compor e que é distinta das costuras lineares do discurso prosaico.

Nesse ponto, torna-se perceptível onde se cruzam as veias da poesia no Ocidente e no Oriente. Se, no Ocidente, a poesia nasceu da submissão ao som, a poesia levou essa submissão a tal ponto de saturação que, explorando até o extremo o potencial da linguagem para os jogos fônicos, gerou estruturas correlativas correspondentes aos processos ideogrâmicos de composição da linguagem, típicos do Oriente. Das formas musicais da poesia, passou-se, portanto, à música das formas. A poesia oriental, por seu lado, poesia inscrita na plasticidade da ideografia e, consequentemente, morfogeneticamente configurada como verdadeira música das formas, também apresenta, nos ritmos visíveis de suas cadeias quase fílmicas, profundas analogias com os modos de formar dos engendramentos melódicos e harmônicos da sonoridade musical.

A descoberta do espaço da página na poesia ocidental, especialmente depois de Mallarmé, Apollinaire, os dadaistas, cummings e, subsequentemente, a poesia concreta e as poesias visuais que se lhe seguiram, deflagrou aí a via mais evidente do cruzamento da poesia ocidental com a oriental. No defrontamento com a visualidade sensível e qualitativa das formas gráficas e com as possibilidades abertas pelo espaço para a configuração das formas, a poesia começou a trazer para a superfície da página, tornando visível aquilo que a poesia ainda colada aos engendramentos da fala deixava subjacente, a saber, seus diagramas associativos internos. Com isso, foi o caráter diagramático da linguagem poética que aflorou na nudez de sua interação com a superfície de seu suporte: o espaço em branco. Condensada na criação de diagramas multiplamente direcionados de palavras, em formas que desenham sentidos, a poesia ocidental reencontrou a brevidade e contensão de meios - síntese radiosa e irradiante - que é própria da poesia oriental: a música das formas.

É certo que essa poesia feita de ritmos visíveis fica muito perto da linguagem plástica, mas dela se diferencia porque, em maior ou menor grau, sempre traz, no seu cerne, uma memória de palavras. Mesmo quando se reduz à mais pura contensão plástica, trata-se ainda de poesia, caso nela brilhem, pelo menos, faíscas ou uma faísca de palavra. É certo também que, quando se diz poesia visível, não se quer compreender simplesmente o visual ótico, mas também e principalmente o visual ideogrâmico. 


\section{Poesia e artes visuais}

Embora a poesia visual possa ser incluída entre as artes visuais, a discussão a seguir será restrita à relação entre a literatura e as artes visuais clássicas da pintura, gravura, escultura e arquitetura. As inter-relações entre o verbal e as artes visuais podem ser estudadas com um foco sobre as diferenças específicas ou sobre as afinidades, semelhanças e influências mútuas entre essas artes irmãs (ver NÖTH, 1990).

\subsection{Diferenças entre a literatura e as artes visuais}

Diferenças evidentes entre o verbal e as artes visuais são aquelas que derivam do potencial semiótico específico dos signos verbais e dos visuais. Tanto a comunicação verbal quanto as artes visuais têm o potencial semiótico da representação, muito embora, em alguns casos, não possam fazer uso dela, como na pintura não representativa ou na poesia sonora. Para representar, a literatura faz uso de palavras que, na terminologia peirceana, são signos essencialmente simbólicos. Pinturas e esculturas, que representam cenas de mundos reais ou ficcionais, fazem-no essencialmente por meio de signos icônicos, mesmo quando eles representam objetos que não existem na realidade.

As artes verbais e visuais divergem quanto ao seu potencial de representação. Imagens visuais são superiores em seu potencial de representar o mundo visível de formas, cores e configurações espaciais, mas com exceção da sinestesia, elas são um meio pobre para a representação do mundo acústico, olfativo, gustativo e tátil da experiência humana. Além disso, as imagens têm um potencial pobre para representar noções abstratas, temporais e relações causais. Elas não têm a faculdade de negar aquilo que elas representam, e não podem expressar a ideia da alternativa entre dois objetos de representação.

Em contraste com as artes visuais, que são tipicamente as artes de representar o mundo visível, as artes verbais podem representar tanto o mundo visível quanto o mundo invisível, impressões sensoriais de todas as modalidades, as ideias abstratas, sentimentos e relações lógicas. É verdade que a pintura tem um potencial alegórico e metafórico que vai muito além dos limites do mundo visível, mas o conhecimento necessário para decodificar uma alegoria pintada pressupõe o conhecimento transmitido pelo literário ou pelos textos bíblicos.

No entanto essa superioridade da semiótica verbal sobre os signos visuais para representar o amplo espectro de fenômenos naturais e culturais não pode ser invocada como um argumento para a superioridade do literário sobre as artes visuais, como foi alegado até a estética do Renascimento. A disputa antiga sobre a superioridade das artes (paragone) foi enganosa. Nenhuma das artes é superior a quaisquer outras. Todas as artes individuais trabalham com seus meios semióticos específicos. Em seu Laocoonte, Lessing (1986) discutiu outras diferenças entre as artes irmãs. Entre as mais fundamentais, encontra-se a diferença nas suas associações com as dimensões de tempo e espaço: a literatura estrutura as palavras em uma sequência temporal, enquanto a pintura estrutura cores e formas em uma contiguidade espacial. A pintura é, portanto, superior quando a representação de objetos no espaço está em causa, enquanto que a literatura é superior quando se trata de representar sequências de ações. Na pintura, o potencial de ações que representam é reduzido a uma mera alusão associada à imagem de um corpo, assim como, na literatura, o potencial de representar os corpos se reduz a sugestões associadas às ações narradas. A separação nítida entre o temporal e espacial das 
artes desenhado por Lessing não se aplica às artes do teatro, dança e cinema, que fazem uso de ambos os modos de representação temporal e espacial.

Baseado em uma semiótica nominalista e em uma "teoria da linguagem da imagem", Nelson Goodman, em As linguagens da arte (1968), tem-se centrado nas diferenças formais entre a literatura e as outras artes. Uma delas é derivada do critério de autenticidade material. Para as pinturas, gravuras, esculturas, o critério de autenticidade é essencial. Goodman chama essas obras de arte "autográficas". A obra de arte é autográfica, quando somente o original corresponde ao trabalho real ou genuíno de arte, nunca sua cópia e, ainda menos, uma falsificação. Obras de literatura e música, ao contrário, são obras de arte alográficas. Para estas, o critério de autenticidade material é irrelevante. A autenticidade de um poema, de um romance ou de uma sinfonia não é perdida com uma reedição ou uma nova edição em qualquer uma das novas cópias do livro reimpresso ou de uma partitura reeditada. As obras dessas artes, que consistem em símbolos discretos, tais como cartas ou notas, são obras de arte alográficas.

A diferença na relação entre as artes visuais e a literatura e a música, segundo o filósofo, deriva dos sistemas semióticos por meio dos quais elas são culturalmente transmitidas. Música e literatura são culturalmente transmitidas na forma de sistemas de notação cujos elementos são símbolos discretos (letras ou notas). Cada único símbolo de um texto literário ou uma partitura musical é semioticamente relevante. Em pinturas, gravuras ou esculturas, por outro lado, não existem elementos discretos. Cada marca, cada linha, cada ponto, e todas as tonalidades de cor e textura são potencialmente significativos. Os elementos das artes visuais são, portanto, densos e repletos de símbolos, de acordo com Goodman. Os elementos de textos literários, por outro lado, não são nem densos nem contínuos, mas discretos e descontínuos. É evidente que o foco dessa caracterização formal das artes versa sobre a disposição sintática e ignora o potencial semântico de um texto literário para criar imagens mentais contínuas não muito distintas dos quadros na sua textura mental.

\subsection{Terreno comum entre a poesia e as artes visuais}

O terreno comum entre a literatura e a pintura tem sido descrito de várias perspectivas. Uma das mais antigas é formulada na antiga teoria do ut pictura poesis (ver OLIVEIRA, 1999). A expressão latina, uma citação de Ars poetica de Horácio (1. 361), significa literalmente "como é a pintura, a poesia também é" ou, como Lessing colocou: "a pintura é poesia muda e a poesia, a pintura falando". A visão semiótica, por trás desse argumento de que a literatura é uma imagem verbal, é que ambas as artes irmãs têm o potencial de representação e de evocar imagens mentais. Os artistas renascentistas referiam-se à comparação de Horácio entre a literatura e a pintura em apoio ao pedido referente à igualdade das duas artes irmãs contra o fundo da antiga tradição medieval que tinha incluído a literatura, mas não a pintura, no cânone das sete artes liberais .

Uma vez que tanto a literatura quanto as artes visuais são artes representativas, outro ponto em comum entre as artes irmãs encontra-se no seu objeto de representação. Temas mitológicos, por exemplo, são tratados em poemas, dramas, bem como em pinturas e esculturas. Batalhas de paisagens podem ser descritas verbalmente em um poema ou em um romance, ou podem ser visualmente representados em uma pintura de gênero.

O dispositivo literário da ekphrasis é o paradigma de um metassigno estético. É um signo da arte verbal cujo referente é um signo de uma obra de arte visual. A ekphrasis literária testemunha o potencial da literatura para a criação de imagens mentais, mas, ao mesmo tempo, a insuficiência da linguagem como um meio de evocar cenas visuais em todos 
os seus detalhes. A tradição da ekphrasis em poesia e prosa nunca foi discutida como um dispositivo para provar a superioridade de uma arte sobre a outra. É interessante, neste contexto, que não há contrapartida para a ekphrasis no que se refere a um dispositivo retórico que descreva uma peça musical por meio da linguagem.

\subsection{Relações intermídia e transmídia}

Relações intermídia e transmídia constituem um terreno comum entre o verbal e as artes visuais, cuja importância tem aumentado com o crescimento e disseminação dos meios de comunicação na cultura contemporânea (ver RAJEWSKY, 2002 e JENKINS, 2008). As relações intermídia da literatura e das artes visuais dizem respeito às influências mútuas das artes irmãs e às possibilidades e limitações da tradução intersemiótica de uma arte para a outra (Plaza, 1987). O estudo da intermidialidade lida com as transformação dos mitos, poemas, novelas nas suas diversas adaptações para as artes visuais, bem como as formas de representação e processos de transformação de obras de arte visuais para a literatura. Obras da literatura tornaram-se os chamados pré-textos, a fonte para adaptações em pinturas, filmes, quadrinhos, vídeo, games e arte digital. Ao mesmo tempo, a literatura tem absorvido e adaptado motivos, enredos, e até mesmo modos de escrever (por exemplo, "a escrita fílmica") das artes visuais e assumiu um diálogo intermidiático com as artes visuais nas suas reflexões literárias sobre as artes irmãs. Além disso, as artes literárias e visuais tornaram-se entrelaçadas em muitos tipos de formas de arte híbridas e multimídia. A passagem da poesia visual para a e-poesia tem sido um tema recorrente na teoria poética contemporânea (ver SANTAELLA, 2007, p. 329-352). Especialmente o teatro tornou-se um cruzamento de intermidialidade desde que o rádio, a televisão, as videoinstalações e as artes digitais passaram a pertencer ao repertório padrão das produções teatrais.

Sob a influência das outras artes, o próprio conceito de literatura mudou desde que a literatura e as artes visuais tornaram-se formas mistas e híbridas de arte. As relações transmídias das artes literária e visuais referem-se às características que as artes têm em comum, independentemente de seu gênero ou mídia empregada. Entre elas, as características que as artes têm em comum durante uma época específica ou período estilístico estiveram no centro da atenção dos estudiosos (ver SOURIAU, 1969; MUNRO, 1969; STEINER, 1981; RILEY, 1995). Temas como a busca de características comuns do Barroco na poesia, pintura, escultura e arquitetura (ver WÖLFFLIN, 1986), as características góticas na obra de Chaucer, ou os traços do cubismo na prosa de Gertrude Stein e na prosa de Oswald de Andrade são exemplos das relações intermidiáticas das artes.

\section{Conclusão}

Com a convergência das artes em gêneros híbridos, tais como as artes midiáticas e digitais, com o entrelaçamento intermidiático de todas as artes, com a reme(i)diação visual e tonal das artes literárias de um lado, e os elementos de absorção da literatura pelas artes irmãs de outro lado (ver BOLTER e GRUSIN, 2000), o conceito de literatura e a relação entre a literatura e as outras artes mudaram profundamente. A literatura digital, por exemplo, não é mais produzida em livros impressos, como costumava ser há séculos. A página foi substituída pela tela; a impressão foi substituída por pixels. No entanto, a literatura não perdeu, mas ganhou visibilidade nas artes não literárias, especialmente, é claro, nos filmes. Mesmo o teatro, uma vez que o paradigma da convergência do verbal com as artes visuais, alargou o seu potencial de uma arte verbal falada pelos atores em um palco 
para uma arte multimídia, passou a incluir a fotografia, os filmes de artes, música, vídeo e outros. Embora a literatura não tenha desaparecido e, de fato, não desaparecerá como uma arte verbal, o crescimento da intermidialidade em todas as artes e os processos de convergência transmídia diminuiu a relevância das questões relativas à especificidade das artes individuais, questões que perderam a importância que já tiveram ao longo da história e da estética.

\section{REFERÊNCIAS}

BOLTER, Jay D. \&GRUSIN, Richard.Remediation.Understanding new media.Cambridge, Mass.: MIT Press, 2000.

CAMPOS, H. de. Ideograma, anagrama, diagrama: Uma leitura de Fenollosa. In:

(Ed.).Ideograma. São Paulo: Cultrix, 1977.p. 115-162.

ECO, U. Opera aperta. Milan: Bompiani, 1962.

FENOLlOSA, E. The Chinese Written Character as a Medium for Poetry(ed. E. Pound). San Francisco, CAL: City Lights Books, 1936/1969.

GOODMAN, N. Languages of Art.Indianapolis:Hackett, 1968.

JAKOBSON, R. Linguística e comunicação. Trad.Izidoro Blikstein. São Paulo: Cultrix, 1971.

JENKINS, Henry. Cultura da convergência, Susana Alexandria (trad.). São Paulo: Aleph, 2008 .

KANDISNKY, W. Do espiritual na arte. Porto Alegre: Dom Quixote, 2010.

LESSING, G.E. Laokoon-oderüber die Grenzen der Malerei und Poesie, Stuttgart: Reclam, 1766/1986).

MITCHELL, W.J.T. Iconology: Image, Text, Ideology. Chicago, IL: Chicago Univ. Press, 1986.

MITCHELL, W.J.T. Picture Theory:Essays on Verbal and Visual Representation. Chicago, IL: Chicago Univ. Press, 1994, 446 p.

MUNRO, T. The Arts and their Interrelations. 2. ed. Cleveland, $\mathrm{OH}$ : Western Reserve Univ. Press, 1969.

NESTROVSKI, Arthur. Tempo, o lugar onde se dá o movimento musical. Folha de S. Paulo. Ilustrada, 3 ago 1986.

NÖTH, W. Handbook of Semiotics. Bloomington, IN: Indiana Univ. Press, 1995.

OLIVEIRA, V.S. de. Poesia e pintura. São Paulo. Unesp, 1999.

PAZ, Octavio. Signos em rotação. São Paulo: Perspectiva, 1972.

PEIRCE, C. S. Collected Papers, vols. 1-6 (eds. Ch. Hartshorne, P. Weiss), vols. 7-8 (ed. K. Burks).Cambridge, MA: Harvard Univ. Press, 1931-58.(Fundamental writings of the founder of modern semiotics).

PLAZA, J. Tradução intersemiótica. São Paulo: Perspectiva, 1987. 
POUND, E. ABC da literatura. Augusto de Campos e José Paulo Paes (trads.). São Paulo: Cultrix, 1970.

PRAZ, M. Mnemosyne: The Parallel between Literature and the Visual Arts. Princeton, NJ: Princeton Univ. Press, 1970/1974.

RAJEWSKY, I. O. Intermedialität. Tübingen: Francke, 2002.

RILEY, C. A.Color Codes: Modern Theories of Color in Philosophy, Painting and Architecture, Literature, Music, and Psychology. Hanover, NH: Univ. Press of New England, 1995.

SANTAELLA, Lucia. O que é semiótica. São Paulo: Brasiliense, 1983.

.Matrizes da linguagem e pensamento: sonora, visual, verbal. São Paulo:

Fapesp/Iluminuras, 2001.

.Linguagens líquidas na era da mobilidade. São Paulo: Paulus, 2007

SANTAELLA, L. \& W. Nöth. Imagem. Cognição, semiótica, mídias. São Paulo: Iluminuras, 1998.

SOURIAU, É. La correspondance des arts. Paris: Flammarion, 1969.

STEINER, W. Image and Code. Ann Arbor, MI: University of Michigan, 1981.

WÖLFFLIN, H. Renaissance und Barock.Munich, 1888/1986.186 p.(Classical study of the affinities between the arts styles in the course of history.)

Lucia Santaella é pesquisadora I-A do CNPq, professora titular da PUC-SP com doutoramento em Teoria Literária na PUC-SP em 1973 e Livre-Docência em Ciências da Comunicação na ECA/USP em 1993. É Coordenadora da Pós-graduação em Tecnologias da Inteligência e Design Digital, Diretora do CIMID, Centro de Investigação em Mídias Digitais e Coordenadora do Centro de Estudos Peirceanos, na PUCSP. É presidente honorária da Federação Latino-Americana de Semiótica e Membro Executivo da Associación Mundial de Semiótica Massmediática y Comunicación Global, México. É correspondente brasileira da Academia Argentina de Belas Artes, eleita em 2002. Foi Vice-Presidente da Associação Internacional de Estudos Semióticos, 1989-1999. Foi também Vice-presidente, em 2006, e Presidente, em 2007, da Charles S. Peirce Society, USA. Foi membro associado do Interdisziplinäre Arbeitsgruppe für Kulturforschung, Universidade-Kassel, 1999-2009. Professora visitante na Frei Universität-Berlin, 1987, na Universidade de Valencia, 2004, na Universidade de Kassel, 2009 e na Universidade de Évora, 2010. Fez repetidos estágios de pós-doc (Fullbright, Fapesp, CNPq, Capes, DAAD). Recebeu o prêmio Jabuti em 2002 e 2009, o prêmio Sergio Motta, em 2005 e o prêmio Luiz Beltrão em 2010. Organizou 11 livros e, de sua autoria, publicou 35 livros. Além dos livros publicou perto de 300 artigos em livros e revistas especializadas no Brasil e no Exterior. 
CASA, Vol.9 n.2, dezembro de 2011

Winfried Nöth é professor titular de linguística e semiótica na Universidade de Kassel, Alemanha e professor convidado na pós-graduação em Tecnologias da Inteligência e Design Digital, da PUCSP. Recebeu em 1971, o prêmio de melhor tese de doutorado, na Universidade de Bochum, Alemanha. Em 1985-86, foi professor visitante, pela Fulbright, na Universidade de Wisconsin, USA. Em 1992, recebeu o prêmio de melhor livro acadêmico pelo seu Handbook of Semiotics. Foi diretor da Faculdade de Inglês e línguas românicas, na Universidade de Kassel, de 1982 a 1983 e de 1995 a 1997. Em 1991, foi eleito membro honorário da Associação Internacional de Semiótica Visual. Foi Diretor do Centro de Pesquisa Interdisciplinar de Cultura, na Universidade de Kassel. Além de centenas de artigos publicados em revistas especializadas internacionais, entre seus livros estao incluídos: Strukturen des Happenings (1972), Dynamik Semiotischer Systeme (1977), Literatursemiotische Analysen (1980), Handbuch der Semiotik (1985), Handbook of Semiotics (1990), Origins of Semiosis. Sign Evolution in Nature and Culture (org., 1994), Semiotics of the Media. State of the Art, Projects and Perspectives (org., 1997), Self Reference in the media (ed., 2007).Seu Handbook of Semiotics está sendo traduzido para o italiano pela editora Bompiani e para o português pela EDUSP. A 2a. edição revisada e aumentada de seu Handbuch der Semiotik foi publicado pela editora Metzler, em 2000.

Recebido em: 10.07.11

Aprovado em: 03.09.11 